\title{
Autonomy and automatons: managed care in the USA
}

\author{
Kwame McKenzie
}

Managed care is a phrase on the lips of every US psychiatrist. Some believe that this revolution in health care has brought US doctors kicking and screaming into the age of 'cost-effective', 'evidence-based medicine' (Mechanic, 1997). But most psychiatrists I interviewed from Boston, San Francisco and New York, thought it had transformed them from autonomous professionals to automatons.

Defining managed care is difficult. In a nutshell, managed care is the collective name for a number of mechanisms used to curb health spending, all of which make cost of care an important factor in clinical decisions by increasing the level of financial risk for providers and limiting the risk for insurers (Iglehart, 1996).

But to really understand what managed care is and why there is so much concern about it one needs to understand how medical care is paid for in the US, how schemes work and who has been affected by the change.

\section{Who pays?}

Health care in the US is insurance based. Insurers, or companies who insure themselves, pay providers for the care they deliver. Patients often have to pay a proportion of the costs. Psychiatric care is provided by community teams and private and public hospitals. Fifty per cent of US citizens have private health insurance provided or subsidised by their employer. Those without private insurance are either covered by the Government's insurance or are uninsured and rely on charity or free care.

There are two Government schemes: Medicaid (12\% of citizens) and Medicare (14\% of citizens) (US Census Bureau: www.bls.census.gov/cps/ pub/pubempbe.htm). These are paid for by the federal Government but administered by state government. Actual coverage and provision varies from state to state. Medicaid covers twothirds of the unemployed and some low income groups. Medicare covers those over 65.

Employers do not have to provide insurance. Three-quarters of the $18 \%$ of Americans who have no medical insurance are in families headed by someone in work. They have no cover because their employers do not offer it and they cannot afford to buy health insurance privately (Kaiser/ Commonwealth Fund 1997). Immigrants are not covered by Medicaid.

The headline figure for cover does not tell the whole story. Insurance is often not comprehensive; some estimate that over $35 \%$ of people under 65 years of age lack adequate insurance coverage (Kaiser/Commonwealth Fund 1997). The situation is worse for those with a mental illness. Private health insurance usually limits liability for psychiatric care and can leave people with serious psychiatric illnesses with no cover (Iglehart, 1996).

Care for the uninsured is funded partly by the federal and state governments and partly by a Robin Hood system: the 'rich', Medicaid and private insurers, over-pay providers for patients and this 'excess' is used to pay for the 'poor' uninsured.

\section{Why managed care?}

Managed care came about because medical spending was perceived to be out of hand. Private insurance schemes and companies were the first to introduce it. Before the advent of managed care, the predominant payment modality was fee for service. Providers decided what care was needed and what it would cost. They sent their bills to insurers who rarely questioned fees and passed on the cost in higher premiums to the policy-holder, usually a company (Iglehart, 1996).

Between 1986 and 1990 spending by employers on mental health and substance misuse services (known collectively as behavioural care) increased by $50 \%$. This percentage increase far outstripped those for other areas of medicine. Companies wanted to curb spending and limit their liabilities and managed care was seen as a solution. By $1994,57 \%$ of people with private insurance had managed behavioural care (Iglehart, 1996).

As the former head of the federal community mental health centre programmes explained:

"The greatest contributors to the development of managed mental health care, a development they 
now bemoan, have been the service providers themselves, practitioners and facilities. By not paying attention to or not caring about costs and length of treatment, they killed, or at least seriously wounded. the goose that laid the golden egg." (Feldman, 1992)

\section{How does managed care work?}

Managed care organisations are set up by insurers or companies to manage the health of their enrollees. They may also contract out this task to a health maintenance organisation (HMO). HMOs may work for profit or as nonprofit organisations.

Some HMOs have their own network of salaried providers. Other HMOs, and managed care organisations, have a network of preferred providers', these are non-salaried providers who see their patients usually at a set cost. Many schemes have a mixture of both with differing levels of benefits and providers organised in different ways depending on the service requested.

There can be yet another layer of complexity. Managed care organisations and HMOs often do not think they have the expertise to run substance misuse or mental health services so they contract these out to specialised behavioural care organisations. These generally run on a for profit basis and often use their own preferred provider network of care delivery.

Managed care curbs spending and makes cost a key issue in the clinical decision-making process. Costs are kept down by limiting the use of services. A number of techniques have been used to this end:

(a) the insurer only pays if a patient goes to facilities and doctors who they approve;

(b) the insurer sets the level of remuneration for services:

(c) the insurance company reviews the decisions that providers make and closely monitors high cost treatment;

(d) the insurance plan limits the amount of care it pays for (a plan could allow 20 outpatient visits and 30 in-patient days a year); and

(e) the insurer gives a set budget to the provider to cover patient care.

Close monitoring of expensive treatment is perhaps the most irksome facet of managed care. Companies employ in-house case reviewers usually with social work, psychology or psychiatric nurse training. Doctors may need to get direct authorisation for expensive care. In-house reviewers use protocols to 'help' providers increase the use of the least expensive service given a particular problem - out-patient care is pre- ferred to in-patient care. These sorts of arrangement have received a bad press because some behavioural care companies are inflexible and have protocols which do not seem to be evidencebased.

There is a closer integration of the financing and delivery of health care under managed care. Providers bear part of the financial risk and so there is an increased incentive to be cost conscious (Folland et al, 1993). This increased financial risk comes from two sources: first, patients and providers are liable for the cost of any care which is not covered by the plan and. second, large managed care organisations try to set levels of payment for services as low as possible using the threat of providers losing their 'preferred' status (and so patients) as leverage.

Managed care has left psychiatrists in the US with much less clinical autonomy. Care offered is limited by managed care companies and hospitals because they are loath to give non-insured care that they have to pay for (Schlesinger, 1996).

\section{How does it work in practice?}

Typical scenarios are as follows. If a patient thinks they need psychiatric help they ring a tollfree number, the reviewer listens to the complaint and schedules an appointment with one of their authorised providers (20\% psychiatrists, $40 \%$ psychologists, $40 \%$ psychiatric social workers). Care from then onwards is limited to that which is expressly covered by agreement between the provider and the company. Filling in the wrong form or using the wrong code for the procedure you have undertaken can result in care not being covered.

Some HMOs will refer callers to a primary care physician, whom they will have to see in order to get a referral to a specialist.

Psychiatrists who want to admit a patient who has private health insurance needs to call the company to get this authorised (behavioural care companies do not put a lot of resources into answering doctors' queries and time on hold or in voice-mail loops can be considerable.) If the case reviewer is unable to find an alternative, hospitalisation will be agreed but time limited, say to five days. If the patient still needs to be in hospital at the end of this time, the psychiatrist will have to ring back to request more time (again it can take a long time to get through and to get care authorised). An extended period of hospitalisation may or may not be authorised depending on the patient's progress. The behavioural care company may refuse to pay for further hospitalisation and suggest discharge, out-patient follow-up and visits by a community case manager. If the psychiatrist does not agree and the patient 
has no other means of payment, the hospital has to pay for the care that the doctor thinks is clinically needed. This money will come from their 'profits' or Robin Hood cross funding from Medicaid or other state or federal grants.

Patients with chronic illnesses become 'uninsured' when their care needs exceed that covered by their policy. If uninsured care is predominantly undertaken by state hospitals and they are in a private hospital they may be transferred or discharged.

\section{What are the effects?}

Managed care removes the incentives for overutilisation of care and investigation which there were in the system previously and tempers the aggressive use of technology which characterised US medicine. It restores the role of primary care and long-term desire to decrease the use of services offers the potential for more preventive medicine. It is simply good business to keep those who are insured as well as possible for as long as possible. Managed care could improve the services offered to patients if thoughtful evidence-based practice standards are used (Mechanic, 1997).

However, to date there is little data on the impact of managed care for patients. Managed care companies believe that they have saved money without a negative impact on outcome and there is little current data which proves otherwise. Anecdotally, patients are faced with more limited and fragmented care and doctors claim that patients trust them less because the role of cost in decision making is explicit.

Managed care has led to less money going to patient care for a number of reasons. First, though $10 \%$ of total health costs are mental health costs, HMOs and insurers only allocate 3$15 \%$ of their budgets on average to the behavloural health care companies to which they contract out care. To balance the books, behavioural care companies often offer less cover and pay providers less. Second, contracting out management of services to behavioural care companies produces another layer of bureaucracy which has to be paid for. Third, behavioural care companies are often for-profit companies and have to take their profit out of the money they are given (Iglehart, 1996).

Managed care also effects the uninsured; the lowered payments to providers mean that there is less scope for Robin Hood cover for the uninsured. It has also changed the breadth of care on offer, hospitals have closed or merged and some of the best known psychiatric hospitals are in financial trouble - expensive providers may not make it on to the list of authorised facilities.
Under managed care psychiatrists have less autonomy. Insurers limit length of stay and pressure doctors to discharge patients early. Hospitals also limit length of stay and discourage doctors from admitting severely ill patients and the uninsured (Schlesinger et al, 1996). Some psychiatrists claim that their salaries have gone down. The aim of many behavioural care protocols is to decrease access to psychiatrists and so they see fewer patients. There is less money for psychotherapy.

The situation is more acute for academic psychiatrists. Academic psychiatrists are rarely part of the authorised provider network because the teaching function of the institution means that they are often more expensive.

Psychiatrists' jobs have changed. They spend more time filling in forms and they spend more time on the telephone trying to get care authorised. The lack of clinical autonomy and the cash bottom line may decrease the ability to try new approaches and the development of new treatment or management strategies.

There was low morale among the psychiatrists I interviewed. They were bitter. They all claimed that they now had little in the way of job satisfaction. The older psychiatrists were planning to retire as soon as it was financially viable.

\section{The future?}

Impressed by industry's successful cost containment, states are turning over government funded insurance care to behavioural health care companies. Medicaid is increasingly being managed by behavioural care companies.

As with private insurance, companies are given less money than they need, they take out their profits and give less to providers. Limited budgets are likely to mean limited care and an increase in the number of people who are technically 'uninsured'. It also means less money for Robin Hood cross-funding of care for the uninsured-Medicaid overpayments were an important source of cash for subsidy of charity/ free care.

It is unclear whether the 'success' of managed care for private plans can be replicated in the public sector. Psychiatric patients covered by private insurance are very different from those covered by government insurance. Private insurance patients are richer and much less likely to have a serious mental illness or long-term life stresses. It is unlikely that protocols developed for the former will be directly applicable to the latter. Cost cutting in the public sector may have a much more visible negative impact on patient care. Moreover, the people who are most likely to be affected by managed care are the uninsured 
who may increase in number and for whom there will be less money for care.

\section{Conclusion}

Managed care cuts costs. Its impact on patient care is unclear. However, it may have effects on funding of care for the uninsured, especially if more states introduce Medicaid managed care. The impact of managed care on the psychiatrists I interviewed was immense, morale was very low. The long-term impact on psychiatrists and the practice of psychiatry is a cause for concern. Protocol driven medicine may lead to deprofessionalisation and de-skilling.

The psychiatrists I interviewed were certainly being dragged kicking and screaming but whether it was with a world of evidence based and truly cost-effective care is yet to be proved.

\section{References}

Feldman, S. (ed.) (1992) Managed Mental Health Services. Springfield, IL: Charles C. Thomas.

Folland, S., Goodman, A. C. \& Stano. M. (1993) The Economics of Healthcare. Englewood Cliffs, $\mathrm{NJ}$ : Prentice Hall.

IGLEHART, J. (1996) Managed care and mental health. New England Journal of Medictne, 334, 131-135.

KAISER/COMMONWEALTH FUND (1997) National Survey of Health Insurance. Washington. DC: Henry J. Kaiser Foundation.

MECHANIC. D. (1997) Managed care as a target of distrust. Joumal of the American Medical Association, 277. 1810-1811.

SCHLESINGER, M., DORWART, R. \& EPSTEIN, B. (1996) Managed care constraints on psychiatrist's hospital practices: bargaining power and professional autonomy. American Journal of Psychiatry, 163, 256260.

Kwame McKenzie, Harkness Fellow and Visiting Scholar, Department of Social Medicine, Harvard Medical School, Boston, MA 02115. kwamemck@ warren.med.harvard.edu

\title{
Camberwell Assessment of Need Scales
}

\author{
Mike Slade, Graham Thornicroft, Linda Loftus, Michael Phelan \\ \& Til Wykes
}

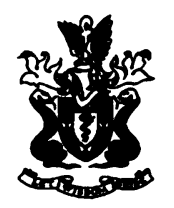

The Camberwell Assessment of Need (CAN) is a tried and tested approach to assessing the needs of the severely mentally ill which is suitable both for research studies and routine clinical use. Developed by staff at the Section of Community Psychiatry (PRiSM), Institute of Psychiatry, the CAN is suitable for use in primary care settings, specialist mental health teams, and social services. It will be of particular interest to care managers and mental health staff who wish to meet the legal requirement that the severely mentally ill receive a comprehensive needs assessment.

\section{January 1999, Etba, 144pp approx, ISBN 1901242250}

Available from Book Sales, Royal College of Psychiatrists, 17 Belgrave Square, London SW1X 8PG

Tel +44 (0) 1712352351 (extension 146), Fax +44 (0) 1712451231

The latest information on College publications is available on the Internet at unwrcpsych.ac.uk 